\title{
Understanding Sexual Negotiation between Marital Partners: A Study of Ogu Families in Southwestern Nigeria
}

\author{
By \\ and \\ Isiugo-Abanihe, Uche C. \\ Department of Sociology \\ Faculty of the Social Sciences \\ University of Ibadan, Ibadan \\ Nigeria
}

Wusu, Onipede

Faculty of Social Sciences

Nigeria

\begin{abstract}
Studies on African sexuality have concentrated on men extra-marital affairs and a total neglect of sexual negotiation between husband and wife. The main objective of this study is to examine gender differentials in sexual negotiation strategies between marital partners among the Ogu, South-western Nigeria. Data were generated from survey conducted among 900 married men and women and 9 focus group discussions. Analysis reveals that both husband and wife have sexual needs that make them to desire sex naturally. While men do make direct demand for sex, women employ indirect erotic strategies to initiate sex. The consent of both partners is required for sexual encounter to give maximum pleasure. Logistic models show that urban residence and frequent spousal communication are associated with gender equity in sexual negotiation between marital partners. It is suggested that sexual health programmes should therefore focus on both partners and not just men.
\end{abstract}

Keywords: Sexual, Relations, Negotiation, Marital, Partners

\section{Résumé}

Des études sur la sexualité africaine sont portées sur les relations extra-conjugales des hommes et sur une négligence totale des négotiations sexuelles entre mari et femme. L'objectif majeur de cette étude est d'examiner les comportements des sexes dans les stratégies de la négotiation sexuelle entre les couples parmi les Ogu, au sud-ouest du Nigeria. Des données ont été obtenues à partir des enquêtes menées parmi 900 hommes et femmes mariés dans 9 groupes de discussion donnés. Les analyses revèlent que le mari et la femme ont des désires sexuels qui les poussent à naturellement désirer le sexe. Le consentement des deux partenaires dans le couple est nécéssaire pour une relation sexuelle avec un maximum de plaisire. Des modèles logistiques montrent que le résidents des villes et une fréquente communication conjugale sont associés avec l'égalité des sexes dans la négociation sexuelle entre mari et femme. Il est suggéré que les programmes de santé sexuelle devraient cependant se focaliser sur les deux partenaires dans un couple et non seulement sur l'homme. 


\section{Introduction}

In a paper presented at a seminar organized by the IUSSP Committee for Reproductive Health, Dixon-Muller (1999) attempted a classical disintegration of reproductive health goals into measurable components. Two of the reproductive health goals she articulated include: freedom from unwanted sexual relations and harmful or unwanted sexual practices, including violence and coercion within sexual relationships; and the capacity to enjoy and sustain sexual relations in a spirit of affection and partnership. These components set sexuality as an integral part of reproductive health. Needless to mention sexual and reproductive health are directly related to the attainment of the millennium development goals (MDGs), especially with respect to improving maternal mortality and combating HIV/AIDS - goals 5 and 6 (Mba 2006).

The WHO (2004) defines sexuality as "a central aspect of being a human throughout life and encompasses sex, gender, identities and roles, sexual orientation, eroticism, pleasure, intimacy and reproduction". In view of this definition, this paper focuses on various sexual negotiation strategies among marital partners in order to re-examine aspects of age-long stereotypical myths on sub-Saharan African sexuality. The main objectives are to examine the context of sexual relation in the regular marriage and relative sexual negotiation strategies between intimate partners in the study setting. The main question addressed in the study is, do men actually dominate sexual negotiation within conjugal unions?

\section{Literature Review and Theoretical Framework}

The field of sexuality is largely understudied in sub-Saharan Africa despite its undisputed importance for reproduction and health (Undie and Benaya 2006; WHO 2004; Vance 1999). The examination of the existing literature on sexuality by Undie and Benawa (2006: 3) "revealed undeniable tension in the emergent body of sexuality literature". Quoting Okami and Pendleton (1994), they affirmed the existence of a contradiction between "empirical data gathering and hypothesis testing and postmodern, post positivist constructionist scholarship/science" on African sexuality. Locally, only a few researchers have delved into this all important area. Among the few studies, there has been concentration on male sexuality with emphasis on extramarital affairs and a total neglect of sexual negotiation between husband and wife (Orubuloye et al. 1995; Boroffice 1995). In addition, majority of the available studies on sub-Saharan Africa do not focus directly on sexuality per se but on the African family system and the HIV/AIDS pandemic (Undie and Benaya 2006). As a result most of the theories constructed on African sexuality are quite tenuous and have been highly criticized (Ahlberg 2007; Undie and Benaya 2006). Perhaps this accounts for the prevailing mystification of sexuality, and especially control over sexuality, between married partners. 
Wusu, Onipede, Isiugo-Abanihe, Uche C.: Understanding Sexual Negotiation between Marital Partners: A Study of Ogu Families in Southwestern Nigeria

The literature is replete with assertions that because African society is largely patriarchal, men dominate family decision-making. The extension of this reality to sexuality appears to fuel some discord in the literature on who really determines timing and the frequency of sex between heterosexual married partners. Some studies report that men are relatively stronger in sexual negotiation in conjugal unions than their female counterparts (Isiugo-Abanihe 1994; Oyekanmi 1999), and that women cannot resist sexual advances from their husbands even when they perceive their health is at risk (possibility of contacting STIs) (Bammeke 1999; Adewuyi 1999). In essence the position established by scholars indicates that women are at a disadvantage in sexual negotiation relative to their husbands' privileged and stronger position in African culture.

However some other studies have indicated that women exact considerable influence in negotiating sex in marriage. Orubuloye (1995: 231) observed that "Yoruba women would increasingly refuse to have sex with partners that are infected with HIV/AIDS". This was attributed to "their economic independence, the ease with which they could break up marriages and return to their families of origin, and the traditional expectation that it is primarily women who are responsible for ensuring that sexual relations do not take place during pregnancy and the postpartum period". Beside this, Orubuloye, Caldwell and Caldwell (1991) reported from a survey in Ekiti that at least 77 percent of female respondents indicate that they refuse sex to their husbands. Again, in a study conducted by Orubuloye et al. (1997) in Ekiti, it was reported that about 70 percent urban and 75 percent rural women claimed to have the right to resist sexual advances by their partners, particularly when they suspect that their husbands are engaged in extra-marital affairs. Also Ogunjuyigbe and Adeyemi (2005) observed in a study carried out in Lagos metropolis that women have some control over their sexuality in Africa, especially during breastfeeding, pregnancy, menstruation and sick period. In view of these discordant voices on the subject matter in Nigeria, more studies are needed. This justifies the present study.

A number of conceptual perspectives have been advanced on global sexuality namely psychoanalytic perspective, learning perspective, script theory and evolutionary psychology perspective (Padgug 1999). The emphasis of these perspectives ranges from conceiving sexuality as a powerful drive to the shaping effect of culture and society on human sexuality. There is no doubt that these existing theories are characterized by limitations as outlined by Undie and Banaya (2006). In this study we propose a bio-cultural conceptual framework for understanding sexuality in the Ogu marital context (figure 1). The focus on this region is predicated upon reports of earlier studies that significant differences exist between this and other parts of Africa in gender relations, especially married couples (Orubuloye, Caldwell and Caldwell 1991) 
This approach stipulates that an inseparable interaction exists between biology and culture as determinants of sexuality between marital partners. There is a biological basis of sexual feelings which is common to both sexes. As Padgug (1999: 18,19 ) observes, "biological sexuality is the necessary precondition for human sexuality". The biological aspect of sexuality is rooted in the fact that every normal man or woman (boy or girl) possesses the sexual instinct to desire sex beginning from puberty. This is universal and it has nothing to do with inequality in the access material resources. This suggests that married women have as much need for sex as are their husbands, and this is natural (Foster 2000).

However, in human society, culture works upon biological sexuality to provide a framework for its manifestation and operations. Padgug (1999: 19) observes that "biological sexuality is only a precondition, a set of potentialities, which is never unmediated by human reality, and which becomes transformed in qualitatively new ways in human society". Culture is thus a human creation in society that shapes and spells out socially acceptable utilization of sexual drive inherited from biology. Thus human biology and culture affect sexuality. "It is as important to avoid a rigid separation of nature and culture as it is to avoid reducing one to the other, or simply uniting them as an undifferentiated reality" (Padgug 1999: 19). Thus culture and biology are equally important in human sexuality. As observed by the WHO (2004), sexuality is influenced by the interaction of biology, psychology, social, economic, political, cultural, ethical, historical, religious and spiritual factors. Sexual urge is amendable to culture and this is why mode of sexual expressions is culture-specific. While the foundational biological sexuality is cross-cultural, the culture-specific aspect which provides operational framework is not universal.

The foregoing discussion shows that in marital relationship both men and women are biologically and culturally sexually active-both husband and wife have sexual needs and desires. The expression of this innate biological sexuality is culture specific and subject to changes. In African context, it is common for men in patriarchal setting to initiate sexual relations and to openly express their sexual desires. This may not imply the unrealistic female subjugation explanation that has dominated African gender debate and reproductive health literature (Ahlberg 2007; Undie and Benaya 2006). It should also be noted that sexual needs is common to both male and female in marital relationships, however culture defines its expression (Undie and Banaya 2006). It is within this framework that the present paper empirically examines sexuality among the Ogu. 
Wusu, Onipede, Isiugo-Abanihe, Uche C.: Understanding Sexual Negotiation between Marital Partners: A Study of Ogu Families in Southwestern Nigeria

Fig. 1: Bio-Cultural Framework of Marital Sexuality among the Ogu of Nigeria

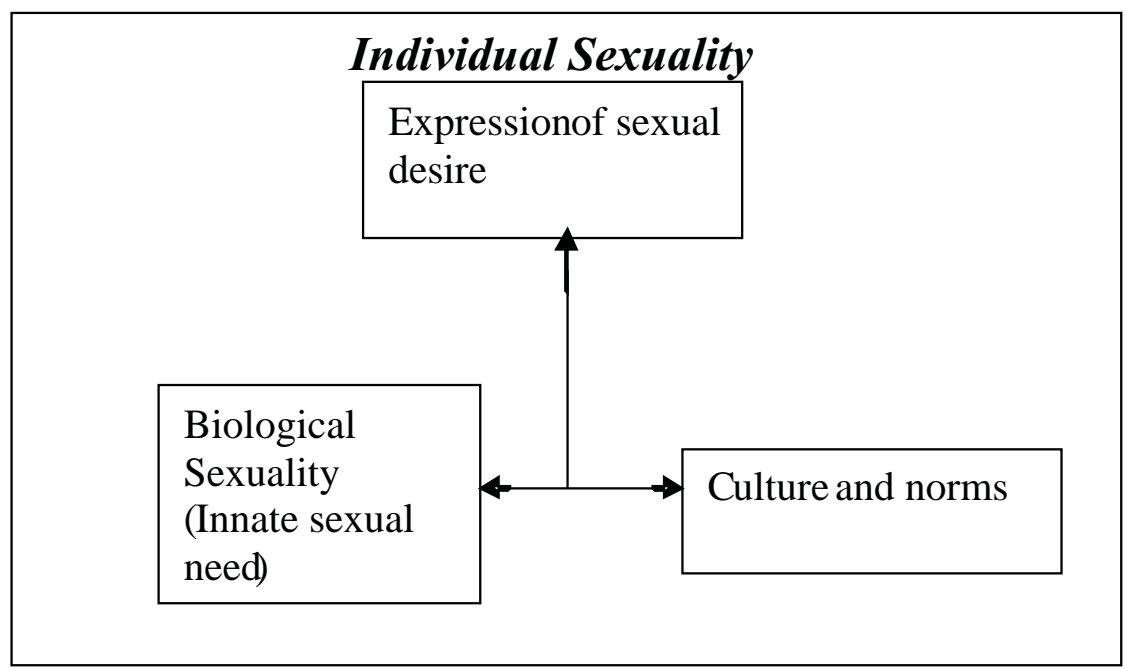

\section{Data and Methods}

The study was conducted among the Ogu (Egun speaking people of Southwestern Nigeria). They are particularly concentrated in Lagos and Ogun states. The people constitute a minority ethnic group settled in hamlets, villages and towns scattered along Yewa Creek (now Badagry creek) in both Lagos and Ogun states. They are found in four local government areas in the two states: Badagry (Lagos state), Ipokia, Ado-Odo and Yewa (Ogun state). This population was chosen for this study mainly because of the scanty information on the group in demographic literature.

The analysis presented in this paper is based on quantitative and qualitative data collected in the study population by the authors. Nine focus group discussions were conducted to generate qualitative data. Three criteria were applied in forming the discussion groups: location, sex of participants and age. Four FGDs were conducted in urban (Badagry township) and five in rural locations (selected villages). Five discussion groups were organised among women and four among men. In Badagry township, two FGDs each of male and female groups were organized, and three female and two male groups were organised in five villages. Due to the small size of most of the villages, some FGDs groups were organised among participants drawn from two villages to get the desired minimum number of participants.

The groups were organised among purposefully chosen members of the study population. There are two categories of the members in terms of their sociodemographic background. The first category consists of four groups organised among members between 20 and 30 years of age with similar socio-economic 
background. On the other hand, the second category consists of five groups organized among participants who are 31 and above years of age, and of comparable socioeconomic characteristics.

In order to enhance the quality of data, the FGD guide was designed in line with the objectives of the study. In addition, the moderator follow up important leads with probes through which more rounded views were generated. The moderator controlled and kept under check individuals who manifested the tendency to dominate group discussion. By this, every participant of the FGDs was encouraged to contribute in every segment of the discussions. This was also facilitated by the fact that all the discussions were carried out in the general dialect spoken among the Ogu. To ensure that no view expressed in the group discussions was lost, the discussions were taped, after obtaining permission from participants. The tapes were transcribed, sorted and content analysed manually.

After the analysis of the FGD data, a structured questionnaire was developed and pre-tested. This was administered among 900 respondents selected through a multi-stage sampling procedure. The study population for the survey was married men and women aged 15 to 65 years in the study setting. The sampling exercise in Badagry township, the only urban settlement mainly inhabited by the Ogu, followed these stages. First, a list of the major streets (called quarters) in the township was prepared. There are eight of such streets, namely. Ahofiko, Asago, Awhajigo,
Boeko, Ganho, Jegba, and Posuko. Second, through simple random process, four of these major streets were selected. Third, at this stage, a census of the buildings in use on each of the streets selected was conducted. Fourth, the aim was to get 50 percent of the respondents from the urban area to interview married men and women separately in two households in every building selected. A household here connotes a house unit inhabited by a man, wife (wives) and children. A total of 113 buildings were systematically selected in the chosen quarters. The sampling fraction was approximately $1 / 5$. After choosing the first building randomly, every fifth building was included in the sample. Finally, in each of the buildings so selected, eligible male and female members of the households, selected via simple random process, were interviewed separately, until 50 percent of the sample size was achieved. In polygynous households, one of the wives was randomly selected and interviewed.

In the rural areas, a list of all the villages inhabited by the Ogu that are at least 20 kilometers away from the headquarters of respective Local Government Areas, was first prepared with the assistance of two field assistants. There are 77 of such villages. Fifty percent of these villages were chosen using tables of random numbers. In all, 38 of the villages were chosen. Because these villages are typically small hamlets, in each of the selected villages all the buildings were included in the sample. One household was selected in each dwelling unit through a simple random process. 
Wusu, Onipede, Isiugo-Abanihe, Uche C.: Understanding Sexual Negotiation between Marital Partners:

Finally, eligible members of the chosen household in each building were interviewed. A total of 442 respondents were interviewed in these rural hamlets.

The analysis of the data comprise of univariate, bivariate and multivariate procedures. In the univariate analysis, the socio-demographic characteristics of respondents were described through the use of frequencies and averages. Bivariate analysis involves the use of crosstabulations relating selected independent variables to the main dependent variable - sexual negotiation defined as the ability of a partner to assert position in sexual issues. The multivariate analysis involved Logistic regression model constructed to explain the main dependent variable. The Logistic regression model is given as:

$$
\operatorname{Logitq}_{i}=b_{o}+b_{i} x_{i}
$$

Where qi is the probability of the outcome given the array of independent variables xi; bo is a constant; and bi is the series of unknown coefficients to be estimated via maximum likelihood. The independent variables are included in the models as dummy variables. The odds ratios and coefficients derived from the logistic regression models are interpreted in relation to the reference category in each independent variable.

\section{Results}

\section{Characteristics of Respondents}

Table 1 provides the selected sociodemographic characteristics of the respondents. The sample included 49.5 percent of males and 50.5 percent of females. About 46 percent and 54 percent of the sample were respectively located in rural and urban places of residence. The relative lack of parity between the two places of residence is largely due to logistic problems experienced in the rural areas characterised by widely dispersed villages and hamlets. The age distribution indicates that husbands are, on the average, 5 years older than their wives. As a rule, here men marry relatively younger women. A similar result was reported for the larger Yoruba group by Oyediran(2002) and Bankole(1992).

The data indicate that the majority of the respondents have had some formal education. However, in term of quantity and quality, men are better educated than their female counterparts. Mean years of schooling for male respondents is about 7.8 relative to 6.2 years for females. In spite of this difference, the level of education among women appears to have risen appreciably in the recent past. This is largely a product of the compulsory and free education programme. The religious affiliation of the respondents indicates that the majority respondents are Protestants. This is the direct effect of recent expansion of Christianity in the area, whereby churches are planted in every nook and cranny of the habitations. 
Table 1: Percentage Distribution of Respondents by selected socio-demographic characteristics and mean values, by sex

\begin{tabular}{|c|c|c|}
\hline Characteristics & $\begin{array}{c}\text { Male } \\
\% \\
\mathrm{n}=440\end{array}$ & $\begin{array}{c}\text { Female } \\
\% \\
\mathrm{n}=449\end{array}$ \\
\hline \multicolumn{3}{|l|}{ Place of Residence } \\
\hline Urban & 58 & 51 \\
\hline Rural & 42 & 49 \\
\hline \multicolumn{3}{|l|}{ Age } \\
\hline$<20$ & 10.9 & 20.3 \\
\hline $20-24$ & 14.3 & 14.6 \\
\hline $25-29$ & 29.0 & 30.0 \\
\hline $30-34$ & 21.6 & 11.8 \\
\hline $35-39$ & 11.0 & 9.9 \\
\hline $40-44$ & 8.0 & 7.6 \\
\hline $45+$ & 5.2 & 5.8 \\
\hline Mean & 38.19 & 33.47 \\
\hline \multicolumn{3}{|l|}{ Education } \\
\hline No Schooling & 12.0 & 24.3 \\
\hline Primary & 35.0 & 31.8 \\
\hline Secondary & 32.3 & 30.3 \\
\hline Post Secondary & 20.7 & 13.6 \\
\hline Mean years of Schooling & 7.75 & 6.23 \\
\hline \multicolumn{3}{|l|}{ Religious Affiliation } \\
\hline Catholic & 13.4 & 13.4 \\
\hline Protestants & 59.5 & 68.2 \\
\hline Muslim & 10.2 & 8.5 \\
\hline Traditionalist & 16.8 & 9.8 \\
\hline \multicolumn{3}{|l|}{ Occupation } \\
\hline Housewife/unemployed & 15.2 & 36.7 \\
\hline Agric/Fishing & 30.2 & 16.7 \\
\hline Petty Trading & 8.6 & 20.7 \\
\hline Private Business & 26.8 & 14.3 \\
\hline Government Worker & 19.1 & 11.6 \\
\hline \multicolumn{3}{|l|}{ Marriage Forms } \\
\hline Monogamy & 70.7 & 76.8 \\
\hline Polygyny & 4.1 & 6.2 \\
\hline Divorced/Separated & 21.3 & 12.9 \\
\hline Widowed & 3.9 & 4.1 \\
\hline \multicolumn{3}{|l|}{ Age at Marriage } \\
\hline$<15$ & 21.1 & 25.8 \\
\hline $15-19$ & 15.9 & 22.5 \\
\hline $20-24$ & 21.1 & 29.0 \\
\hline $25-29$ & 36.4 & 21.8 \\
\hline $30+$ & 5.5 & 0.9 \\
\hline Mean & 24.22 & 20.48 \\
\hline
\end{tabular}

Source: Fieldwork, 2003 
Wusu, Onipede, Isiugo-Abanihe, Uche C.: Understanding Sexual Negotiation between Marital Partners: A Study of Ogu Families in Southwestern Nigeria

The occupational distribution of the sample reveals that the majority of them are self employed. Men are more likely to engage in agriculture-related occupations and private domestic activities, while their female counterparts are mostly housewives or engaged in petty trading. Only about 19 percent of males and nearly 12 percent of females are engaged in whitecollarjobs.

The marriage type indicates that monogamy is more prevalent in the study population owing to the changing social and economic environment that discourages polygynous marriages. Boroffice (1995) has reported that polygyny is declining in the setting mainly due to the spread of Christianity. Marriage is early and universal in the population; the data indicate that by the age of 30 years virtually all the females have married; only 5.5 percent of the men married after age 29 .

The age range of the participants of the FGDs is between 25 and 55 . About 50 percent have had primary schooling, 20 percent secondary schooling and 10 percent possessed post secondary qualifications; approximately 20 percent never had any formal educational training. About half of the participants are subsistence farmers while about 5 percent are civil servants and others are petty traders, craft men/women and medium scale business men and women.

\section{Ogu Marital Sexuality}

This section discusses the issue of sexual negotiation among sampled marital partners in the study setting. An attempt is made here to explain this phenomenon using both qualitative and quantitative evidence.

\section{Quantitative Evidence}

Table 2 shows test of association between sexual negotiation and selected socio-economic variables. On the average, roughly 54.4 percent of the male respondents agreed that when they make sexual demands, the willingness of their spouses determines whether they would succeed or not. The proportion of men who agreed that their spouses can refuse their sexual demands is positively associated with the level of education. This is an indication of more egalitarian conjugal relation among better educated couples. Also wives in urban areas and those living in homes where there is frequent interpersonal communication are more likely to resist sexual advances from their spouses. Men who get married after age 30 and those currently in marriage are somewhat more likely to report that their spouse can refuse sexual advances. 
Table 2: Percentage distribution of respondents reporting spouse having the right to resist sexual advances from the partner by selected characteristics

Characteristics

Education

No Schooling

Primary

Secondary

Post Secondary

Age at first Marriage

$<15$

15-19

20-24

25-29

$30+$

\section{Family Structure}

Extended

Nuclear

Male

(Yes)

49.1 (53)

51.9 (154)

51.4 (142)

70.3 (91)

$\chi^{2}=10.72 * *$

$53.8(93)$

$49.1(70)$

$58.1(93)$

53.8 (160)

$\chi^{2}=10.04 *$

55.9 (254)

54.1 (129)

$\chi^{2}=0.09$
83.3 (24)

Female

(Yes)
35.8 (109)
39.2 (143)
50.0 (136)
60.7 (61)
$\chi^{2}=13.12 * *$

23.3 (116)

46.5 (101)

48.5 (130)

$61.2(98)$

75.0 (4)

$\chi^{2}=34.75 * *$

42.6 (239)

48.6 (143)

$\chi^{2}=1.46$

50.4 (238)

47.9 (73)

34.4 (128)

$\chi^{2}=12.50 * *$

\section{Place of residence}

Urban

$61.4(254)$

59.9 (227)

Rural

46.8 (186)

28.8 (222)

$\chi^{2}=9.31^{* *}$

$\chi^{2}=43.90^{* *}$

\section{Marriage form}

Monogamy

55.9 (311)

44.3 (345)

Polygyny

33.3 (18)

44.3 (28)

$\chi^{2}=3.66$

$\chi^{2}=3.15$

Source: Fieldwork $2003 *$ - significant at $\mathrm{P}<0.05 ; \quad * * \quad$ - significant at $\mathrm{P}<0.01$ 
Wusu, Onipede, Isiugo-Abanihe, Uche C.: Understanding Sexual Negotiation between Marital Partners: A Study of Ogu Families in Southwestern Nigeria

Also, the table shows that it is possible for women to make sexual demand. At least 23.3 percent of female respondents indicated that their partners might resist sexual advances they make. This position is relatively higher among those with post secondary schooling, who married at 20 years and above, of urban residence, nuclear and single parent family structures as well as those who have regular inter-spousal discussion. In addition, the chi-square values show that the right of a spouse to refuse sexual advance to his or her partner is significantly related to education, spousal communication, place of residence and age at first marriage.

Table 3 presents the odds ratios of two logistic regression models (male and female) examining sexual negotiation between partners in conjugal union. From the table, it is obvious that place of residence and spousal communication are significantly related to sexual negotiation between marital partners among the Ogu. According to the table, the place of residence and spousal communication are significantly related to the right of a woman to refuse sexual demand by her spouse. Urban residence is twice as likely to enhance this right as rural residence. While the practice of frequent spousal communication is 2.5 times more likely, less frequent inter-spousal discussion is 1.93 times more likely, to enhance women's power in sexual negotiation than rare practice of spousal communication. So, with respect to the male respondents, frequent practice of spousal communication and urban residence are is important factors that can enhance women's sexual negotiation power in conjugal union.

In a similar vein, the female model indicates that place of residence and spousal communication is significantly associated with sexual negotiation right in Ogu family. While frequent inter-spousal discussion is over three times more likely, less frequent spousal communication is almost three times more likely to promote refusal in sexual negotiation than lack of inter-spousal communication between marital partners. Urban residence is 2.06 times more likely to enhance right to refuse sex than rural residence in conjugal unions in the study setting. It is therefore vivid that urban residence and frequent inter-spousal communication are significant factors capable of enhancing sexual negotiation right of marital partners in the study setting. 
Table 3: Odds ratios from two logistic regression models examining the effect of selected characteristics on spouse's right to resist sexual advances by partner.

Odds ratios

Male

S.E.

Female

Education

$\begin{array}{lllll}\text { Primary } & 1.56 & 0.34 & 1.29 & 0.29 \\ \text { Post Primary } & 1.68 & 0.35 & 1.05 & 0.29 \\ \text { No Schooling (rc) } & 1.00 & - & 1.00 & -\end{array}$

Family Structure

Odds

Nuclear

1.07

0.24

0.63

0.24

Extended (rc)

1.00

-

1.00

Age at first Marriage

$\begin{array}{lllcc}20-24 & 0.89 & 0.23 & 1.33 & 0.24 \\ 25+ & 2.62 & 0.61 & 2.23 & 1.19 \\ <20(\mathrm{rc}) & 1.00 & - & 1.00 & -\end{array}$

Place of Residence

Urban

$2.06 * * \quad 0.23$

$3.55^{* *}$

0.25

Rural (rc)

1.00

-

1.00

Spousal Communication

$\begin{array}{cllll}\text { Frequent } & 2.48^{* *} & 0.26 & 3.44^{* *} & 0.26 \\ \text { Less Frequent } & 1.93 & 0.37 & 2.66^{* *} & 0.35 \\ \text { Rarely (rc) } & 1.00 & - & 1.00 & - \\ \text { Marriage form } & & & & \\ \text { Monogamy } & 0.89 & 0.24 & 0.71 & 0.25 \\ \text { Polygyny } & 1.00 & - & 1.00 & - \\ \text {-2 Log likelihood } & 573.10 & & 550.83 & \\ \text { Model chi-square } & 32.05^{* *} & & 66.26^{* *} & \end{array}$

Marriage form

* - significant at $\mathrm{P}<0.05 ; * *$ - significant at $\mathrm{P}<0.01, \mathrm{rc}-$ reference category

Source: Fieldwork, 2003

\section{Qualitative Evidence}

The evidence from the focus groups indicates that the majority of the participants were of the opinion that men initiate sexual demands. Of course, this is understandable considering the social and cultural climate of the society that has preconditioned women's mind to always wait for men to initiate sex. In fact, most of the participants stated that women seldom express demand for sex, and that if they must make such a demand, they do so discretely and indirectly, for example by 
Wusu, Onipede, Isiugo-Abanihe, Uche C.: Understanding Sexual Negotiation between Marital Partners:

touching sensitive parts of their husbands' bodies. So the issue is not that men dominate sexual negotiation in the family but that men are only culturally bound to initiate sex. The response of a man in one of the FGDs to the question, "who initiates sex between spouses?" buttresses this position:

Men initiate sex because women don't reveal their desires, even when they are interested they would never initiate sexual demand. In some cases they may request sex indirectly by touching

$t \quad$ he bodies of theirhusbands (A man from Badagry, aged 50).

This was the general view in all the FGDs including the female groups. Members of the groups chorused that it is inappropriate and bad manners for women to initiate sex. Other ways women send out erotic messages is through preparing delicious dishes for their husbands, dressing elegantly and being extra-nice to their husbands. At the same time, in all the FGD sessions, members unanimously agreed that there is nothing like force in sexual relation between a man and his wife. They stated that a woman could resist or reject the sexual advances of her husband, if she is not favourably disposed to it. Some male participants mentioned the importance of being polite and wise in such situation.

Most members of the groups opined that there is joy in sex and this pleasure will either diminish or be totally absent when force is applied in it. As a result of this, force is quite uncommon in sexual negotiation in conjugal unions. This view is consistent with Foster's (2000) findings that the joy in sex makes both sexes to mutually desire it in marriage. So among the Ogu a woman waits for her husband, who is culturally expected to initiate sex, to do so; and she will generally oblige provided the husband has been responsible and considerate. Hence, sexual negotiation in families is a mutual exercise between husband and wife. Below are some of the responses of participants on negotiation of sex between husband and wife.

Men initiate sex but their wives may politely refuse when they are not really interested. Men do not force their wives into sex.

(A woman from Badagry, aged 45)

The notion that men control sexuality $n$ the family is not true. Men do not force their wives into sex; women can object only that it must be done wisely. (A woman from Badagry, aged 35)

Men are not the sole initiator of sex; rather it is a mutual thing. (A woman from Iyafin, aged 47)

Anytime the husband needs the wife sexually, it is normal for her to make herself available because it is entrenched in the holy books.

(A woman from Ijotun, aged 42)

If a man is a real man, where there is love and real care, anytime he demands for sex, the wife will always be willing. (A woman from Ijotun, aged 37) 
The above views stress the cultural underpinnings of conjugal relations of roles and mutuality. Men and women are expected to play their respective roles even in sexual initiation. Men are expected to initiate sex, and such moves are rarely refuted if they are responsible. In fact a woman who consistently rebuffs her husband's sexual demand runs the risks of having a co-wife in a culture that permits polygyny.

\section{Discussion}

Sexual negotiation is a crucial issue in reproductive and sexual health decisionmaking. The result of the present study raises a crucial question. Do men actually dominate decisions on sexuality in the family? Although in most cases men are culturally conditioned to initiate sex directly, albeit women too do initiate sex only that they adopt indirect strategies.

The fact that men initiate sex directly may have nothing to do with the popular women subjugation and their supposedly disadvantageous economic position relative to men. This may be more a function of biology as has been observed in the sexuality of some animals. For instance, when female pigs are on heat they are obviously violent and expressly aggressive. As soon as an active boar is introduced, rather than make direct attempt at wooing the boar into sex, the female pig waits for the boar to initiate sex even though she is manifesting a high demand for sex. Clearly the boar does not initiate sex because it is economically stronger than the female pig? It is a function of the innate biological structure. In a similar vein, men are biologically structured and in most part of the world, culturally conditioned to initiate sex.

Do women have any right to refuse sex when their male intimate partners make sexual advances when they are not favourably disposed? The present study suggests that because the joy of sex is maximized when the consent of the two partners is involved, no partner has the total control over when to have sex. In fact, the majority of the male respondents indicated that their spouses have the right to say 'no' when they make sexual advances. On the one hand, this finding is consistent with the conclusions of Orubuloye (1995), Orubuloye et al., (1997), and Ogunjuyigbe and Adeyemi (2005); and on the other hand, it contradicts much earlier findings, essentially rooted in myth of sexuality in sub-Saharan Africa (Undie and Benaya 2006). The conclusions of those studies may be attributed to the failure to distinguish between sexuality in a couple and that of unmarried sexual partners. Unmarried heterosexual partners may be prone to force as a result of the fact that they tend to take advantage of the 'other' anytime opportunity arises. In a couple's sexual relation, coercion may not be a 'normative' practice given that they are in mutual relationship and expected to satisfy the biological needs of each other.

The present study also found that men with high level of schooling tend to possess more positive conjugal attitudes which consequently enhance the right of their wives to turn down their sexual 
Wusu, Onipede, Isiugo-Abanihe, Uche C.: Understanding Sexual Negotiation between Marital Partners:

advances without engendering friction. The logistic odds ratios also show that regular spousal communication and urban residence significantly enhances the right of a woman over her sexuality. However, further studies are needed to investigate the relative power of men and women in sexual intercourse among married couples.

\section{Conclusion}

Through socialization process, men are conditioned to be more sexually expressive than women, and are therefore more likely to initiate sexual advances in a union. Women who refuse sexual advances temporarily are rarely 'forced' into sex, since sexual intercourse is viewed as an act which gives mutual pleasure to both partners, and such pleasure is maximized when partners are in agreement to have sex. That urban residence and more egalitarian conjugal relations enhance a woman's right over her sexuality is expected in view of the liberating influence of modernization and social change often associate with such residential arrangement. As more people embrace such change, spousal equality is enhanced within the home.

The policy implications of the findings include instead of designing sexual health programmes to focus on just men, the sexual health needs of both partners should be given adequate attention in such programmes. Given that egalitarian conjugal relation is enhanced by modernization, it is therefore imperative that governments and NGOs in developing countries should pursue vigorously various development projects aimed at achieving a more modern society, especially programmes targeting improving women socio-economic status. This will empower women and increase their control over their sexual life in unions.

\section{References}

Adewuyi, A. 1999. "Power and Privilege: The Male Issues in Fertility Transition in Nigeria, Sub-Saharan Africa" Pp 3 14. In Proceedings of the Conference on African population in the 21st century. Volume 2, Durban, Union of African Population Studies.

Ahlberg, B. M. 2007. "Rethinking Sexualities in Africa" (A short Review). Studies in Family Planning 38, (2): 142-144.

Bammeke, F. 1999. "Understanding the Gender Question". In Sociology for Beginners pp 191-210, Edited by L. Olurode and O. Soyombo, Lagos: NIDD Limited.

Bankole, S. A. 1992. Marital Partners' Reproductive Attitudes and Fertility among the Yoruba of Nigeria. A Ph.D. Dissertation in Demography, University of Pennsylvania.

Boroffice, O. B. 1995. “Women's Attitudes to Men's Sexual Behaviour". Health Transition Review (supplement) 5: 67-79. 
Dixon-Mueller, R. 1999. Gender Inequalities and Reproductive Health: Changing Priorities in an Era of Social Transformation and Globalisation. Policy and Research Paper, Number 16. Paris: IUSSP.

Foster, C. 2000. "The Limit to Low Fertility: A Biosocial Approach". Population and Development Review 26, (2): 209 217.

Isiugo-Abanihe, U. C. 1994. “Reproductive Motivation and Family Size Preference among Nigerian Men" Studies in Family Planning 25, (3): 149161.

Mba, J. C. 2006. "Reproductive Health and Maternal and Child Health Challenges Confronting Africa". In Reproductive, Maternal and Child Health in Africa: Current Development and Future Direction pp 19-33, Edited by J. C. Mba and E. Ngwe, Dakar: UAPS.

Ogunjuyigbe O. P. and Adeyemi, O. E. 2005. "Women's Sexual Control within Conjugal Union: Implication for HIV/AIDS Infection and Control in a Metropolitan City. Demographic Research 12: 29-50.

Orubuloye, I.O. 1995. "Women's Control Over their Sexuality: Implications for STDS and HIV/AIDS Transmission in Nigeria". In Women's Positon and Demographic Change in Sub-Saharan Africa pp
223- 231, P. M k kinwaAdebusoye and A. J e $\mathrm{n} \mathrm{s}$ e $\mathrm{n}$, Belgique: IUSSP: 223-231.

Orubuloye, I.O., Caldwell, J.C and Caldwell, P. 1995. "The Cultural, Social and Attitudinal Context of Male Sexual Behaviour in Urban Southwestern Nigeria". Health Transition Review 5: 207-222.

Orubuloye, I.O.; Oguntimehin, F. and Sadiq, T. 1997. "Women role in reproductive health decisionmaking and vulnerability to STD and HIV/AIDS in Ekiti, Nigeria" Health Transition Review (Supplement) 7:329 336.

Oyediran, K. A. 2002. Spousal Communication and Fertility Behaviour Among the Yoruba of South-western Nigeria: The Case of Ogbomoso and Iseyin. A Ph.D Dessertation in the Department of Sociology, University of Ibadan.

Oyekanmi, F.A.D., 1999. "Current Themes in Population Studies". In Sociology for Beginners pp 165-190, Edited by L. Olurode and O. Soyombo, Lagos: NIDD Limited.

Padgug A. R. 1999. “Sexual Matters: On Conceptualizing Sexuality in History". In Culture, Society and Sexuality: A Reader pp 15-28, Edited by R. Parker and P. Aggleton, London and New York: Routledge. 
Wusu, Onipede, Isiugo-Abanihe, Uche C.: Understanding Sexual Negotiation between Marital Partners:

A Study of Ogu Families in Southwestern Nigeria

Undie C. and Benaya, K. 2006. “The State of Knowledge on Sexuality in SubSaharan Africa: A Synthesis of Literature". JENDA: A Journal of Culture and African Women Studies, Issue 8.

Vance S. C. 1999. "Anthropology Rediscovers Sexuality: A Theoretical Comment". In Culture,
Society and Sexuality: A Reader pp 39-54, Edited by R. Parker and P. Aggleton, London and New York: Routledge.

World Health Organisation. 2004. Progress in Reproductive Health Research. Geneva:WHO, Number 67 